\title{
Glucagon-like peptide-1 receptor agonist stimulates mitochondrial bioenergetics in human adipocytes*
}

\author{
Joanna Góralska ${ }^{凶}$, Agnieszka Śliwa, Anna Gruca, Urszula Raźny, Monika Chojnacka, Anna \\ Polus, Bogdan Solnica and Małgorzata Malczewska-Malec
}

Department of Clinical Biochemistry, Medical College, Jagiellonian University, Kraków, Poland

Glucagon-like peptide 1 receptor agonists (GLP-1RAs) are relatively new pharmacological agents used to normalize glucose level in type 2 diabetes. Recently, GLP-1RAs have been approved for the treatment of obesity to reduce body weight in non-diabetic patients. The extra-pancreatic effects of GLP-1RAs, as well as their molecular mechanism of action, are still poorly understood. Thus this study was aimed to verify the hypothesis that the mechanism of action of the GLP-1RAs involves mitochondria and that GLP-1RAs administration can improve mitochondrial functions. For this purpose, preadipocytes CHUBS7 were differentiated to mature adipocytes and then stimulated with GLP-1RA, exendin-4 at $100 \mathrm{nM}$ for $24 \mathrm{~h}$. Oxygen consumption rates, mitochondrial membrane potential, intracellular ATP (adenosine triphosphate) level, SIRT1 and SIRT3 gene expression and the histone deacetylases' activity were measured. Exendin-4 was found to uncouple mitochondrial electron transport from ATP synthesis, slightly decreasing mitochondrial membrane potential in mature adipocytes. Routine respiration and uncoupled oxygen consumption rates were higher in exendin- 4 treated adipocytes than in the non-treated cells. The ATP level remained unchanged. Exendin-4 enhanced SIRT1 and SIRT3 genes expression. Histone deacetylases' activity in the nuclear fraction was not affected by exendin-4, although the activity of class III histone deacetylases was increased. All of the effects on mitochondrial bioenergetics induced by exendin- 4 were abolished by addition of glucagon-like peptide 1 receptor antagonist. In conclusion, exendin-4 activates the sirtuin pathway and increases energy expenditure in human adipocytes. Our results suggest another mechanism that may be responsible for body weight reduction observed in patients using GLP-1RAs.

Key words: exendin-4, GLP-1, mitochondria, sirtuin, mitochondrial respiration

Received: 19 March, 2017; revised: 25 June, 2017; accepted: 29 June, 2017; available on-line: 19 August, 2017

e-mail: jgoralska@cm-uj.krakow.pl

* Preliminary data presented in this report had been reported previously at the XLIV Winter School of Faculty of Biochemistry, Biophysics and Biotechnology of Jagiellonian University 14-18 February 2017, Zakopane, Poland.

Abbreviations: ATP, adenosine triphosphate; BAT, brown adipose tissue; Ex-4, exendin-4; ETC, electron transport chain; GLP-1, Glucagon-like peptide 1; GLP-1RA, Glucagon-like peptide 1 receptor agonist; HDAC, histone deacetylases; OCR, oxygen consumption rate; sirt, sirtuin 1; sirt3, sirtuin 3; WAT, white adipose tissue

\section{INTRODUCTION}

Mitochondria are at the center of cellular metabolism and not only provide energy for a variety of metabolic processes but also are central for the coordination and integration of the various pathways defining the cell's metabolic program. It is well established that mitochondria are critically involved in the pathophysiology of metabolic disorders, such as obesity and diabetes (Muoio \& Newgard, 2008). Mitochondrial function also appears to be a critical determinant of insulin sensitivity within the muscle, liver, and adipose tissue (Szendroedi et al., 2011).

Incretins, gut-derived hormones, include glucagon-like peptide (GLP-1) and glucose-dependent insulinotropic peptide (GIP), that are secreted into the circulation at low basal levels at a fasting state but increasing rapidly and transiently following food ingestion. GLP-1 is released in response to food, especially glucose, fatty acids, proteins and bile salts in the bowel. The biological effects of GLP-1 principally include stimulation of insulin expression and insulin biosynthesis (Fehmann et al., 1997). GLP-1 has been also shown to prevent $\beta$-cell apoptosis in animal models of diabetes (Li et al., 2003) and glucolipotoxicity (Buteau et al., 2004). The GLP-1 plasma level is decreased and consecutively the insulinotropic effect of this incretin is diminished in type 2 diabetes, in obesity or after bariatric surgery (Færch et al., 2015). GLP-1 is rapidly degraded in vivo by dipeptidyl peptidase IV (DPP IV) located in various tissues, on the capillary surfaces, as well as present in a soluble form in the circulation, so active GLP-1 (7-36) has a half-life of $2 \mathrm{~min}$.

Short half- life of native GLP-1 has been overcome through the use of chemically modified degradation-resistant glucagon-like peptide 1 receptor agonists (GLP$1 \mathrm{RAs}$ ) in therapy of type 2 diabetes. GLP-1RAs mimic the effects of native GLP-1, which increases insulin secretion, inhibits glucagon secretion, increases satiety and slows gastric emptying (Østergaard et al., 2016). The most often used GLP-1 receptor agonists, exenatide and liraglutide, administered together with oral antihyperglycemic agents have been shown to be effective in the treatment of type 2 diabetes. Exenatide (exendin-4) is a synthetic agonist of the GLP-1 receptor, approved (in 2005 in the U.S., in 2006 in the E.U.) for the treatment of type 2 diabetes (Drucker et al., 2010). Other therapeutic GLP-1RAs, exhibiting a more prolonged duration of action, include liraglutide (approved in the E.U. in 2009), lixisenatide (approved in the E.U. in 2013) and albiglutide (approved in the E.U. in 2014). GLP-1R agonists control blood glucose through stimulation of insulin and inhibition of glucagon secretion (Drucker, 2006). These GLP-1R-related effects are plasma glucose dependent, thereby minimizing the risk of hypoglycemia in the absence of concomitant sulfonylurea therapy (Butler et al., 2010; Feher et al., 2017). 
In addition to glycemic control, the observed effect of GLP-1RAs is the reduction in body weight in the majority of treated subjects (Wadden et al., 2013; Lundkvist et al., 2017; le Roux et al., 2017). This well-documented effect results partially from reduced appetite (through the action on GLP-1 receptors in the hypothalamus) and slowed gastric emptying (McAdam-Marx et al., 2016). Moreover, an ultrasound study documented that even a short course of treatment with exenatide, besides weight loss, induces a redistribution of adipose tissue deposits, possibly contributing to a better cardiovascular risk profile in patients with type 2 diabetes (Morano et al., 2015). After successful trials with GLP-1RAs at a high dose in non-diabetic subjects, the incretin mimetic therapy has been approved (in the U.S. in 2014, and in March 2015 in the E.U.) for treatment of obesity to reduce body weight in obese non-diabetic patients (Anandhakrishnan \& Korbonits, 2016).

Due to the growing interest in incretin therapy, several clinical as well as experimental studies are in progress, although the mechanism of GLP-1RAs action in adipose tissue is not yet sufficiently understood (Majumdar \& Weber, 2010; Chae et al., 2015; Pastel et al., 2016). Thus, our study was aimed to verify the hypothesis that the GLP-1 RA mechanism of action involves mitochondria and that GLP-1RA administration can improve mitochondrial functions. For this purpose, the influence of GLP-1 RA, namely exendin-4, on mitochondrial bioenergetics was studied in the CHUBS7 human adipocytes.

\section{MATERIALS AND METHODS}

Cell culture. All reagents were purchased from Sigma-Aldrich, unless stated otherwise. Human cell line CHUBS7 Nestle Research Center, Lausanne, Switzerland) derived from human subcutaneous adipose tissue, was cultured in a mixture (1:1) of DMEM and F12 culture media. Cells were plated (at a density of $30 \times 10^{3}$ cells $/ \mathrm{cm}^{2}$ ) in DMEM/F12 media supplemented with 10\% fetal calf serum (Gibco, Grand Island, NY, USA). At confluence, the cells were incubated in a basal medium, which was serum-free DMEM/F12 medium supplemented with $15 \mathrm{mM} \mathrm{NaHCO}, 17 \mu \mathrm{M}$ D-panthotenic acid, $15 \mathrm{mM}$ Hepes and $33 \mu \mathrm{M}$ biotin, $10 \mu \mathrm{g} / \mathrm{ml}$ transferrin, $1 \mathrm{nM}$ triiodothyronine, $850 \mathrm{nM}$ insulin, and freshly added $500 \mu \mathrm{g} / \mathrm{ml}$ fetuin. The ChubS7 cells were differentiated into mature adipocytes by adding $1 \mu \mathrm{M}$ dexamethasone and $1 \mu \mathrm{M}$ rosiglitazone to the basal medium for 21 days. Then adipocytes were exposed to GLP-1R agonist, exendin-4 (Ex-4) (100 nM) or to Ex-4 along with GLP-1R antagonist, exendin-9 (Ex-9) (100 nM), for 24 hours.

Cell differentiation assay. The cellular lipid content was assessed by lipid staining with Oil Red-O. Cells were washed twice with PBS and fixed in 3.7\% paraformaldehyde (POCH, Gliwice, Poland) in PBS without $\mathrm{Mg}^{2+}$ and $\mathrm{Ca}^{2+}$ (Biomed, Lublin, Poland) for 1 hour at room temperature. Then, the paraformaldehyde solution was removed, cells were washed shortly with double distilled $\mathrm{H} 2 \mathrm{O}$ and stained with Oil Red-O solution for 1 hour at room temperature. For the staining, $0.5 \mathrm{~g}$ of Oil Red-O was dissolved in $100 \mathrm{ml}$ of isopropanol (POCh, Gliwice, Poland). After 1 hour, the Oil Red-O containing medium was removed and the cells were examined by light microscopy.

Oxygen consumption. Mitochondrial respiration assay was performed using the high-resolution respirometry system Oxygraph-2k (Oroboros Instruments, Aus- tria). Live CHUBS7 cells $\left(1 \times 10^{6}\right)$ were suspended in $2 \mathrm{ml}$ of basal medium containing $5 \mathrm{mM}$ glucose (control cells) or in $2 \mathrm{ml}$ of basal medium containing $5 \mathrm{mM}$ glucose with exendin-4 (Ex-4), exendin-9 (Ex-9) or in a medium containing $25 \mathrm{mM}$ glucose (high glucose control). Oxygen sensors were calibrated routinely at air saturation and in oxygen depleted media. Oxygen consumption was monitored at $37^{\circ} \mathrm{C}$ in a thermostatically controlled chamber. The protocol according to Dunham-Snary and coworkers (2014) was used.

Intracellular ATP content. The intracellular ATP content was measured by using the ATPLiteTM luminescence assay (Perkin Elmer, Waltham, MA, USA), according to the protocol provided by the manufacturer, and the luminescence was measured using a Tecan Genios microplate reader (Thermo Fisher). Data were calculated using the Magellan software. Protein content was measured in the samples of cell lysates by Total Protein Kit, Micro Lowry, Peterson's Modification (Sigma). The ATP concentration was adjusted for protein content in each sample and expressed as nmol ATP/mg of cell protein.

Mitochondrial membrane potential $\left(\Delta \psi_{\mathrm{m}}\right)$. Changes of the $\Delta \psi_{\mathrm{m}}$ were monitored by fluorescent staining of the live CHUBS7cells with JC-1 dye. The cells were incubated with $2 \mathrm{mM} \mathrm{JC}-1$ solution (MitoProbe Assay Kit, Invitrogen Life Technologies, Carlsbad CA, USA) in the dark for $45 \mathrm{~min}$ at $37^{\circ} \mathrm{C}$. Then, the cells were washed, diluted in PBS and analyzed by flow-cytometry (FACSCanto II, BD Biosciences Discovery Labware, Bedford, MA, USA) using $488 \mathrm{~nm}$ excitation with 530/30 nm (FL1, green) and $585 / 42 \mathrm{~nm}$ (FL2, orange) band pass emission filters. Fluorescence of $1 \times 10^{4}$ cells was collected during a single instrument run. The data were analyzed using the FacsDIVA software (BD Biosciences Discovery Labware, Bedford, MA, USA). In live cells, JC-1 exists either as a green-fluorescent monomer at depolarized membrane potentials or as an orange-fluorescent J-aggregate at hyperpolarized membrane potentials. The mitochondrial membrane potential was quantified by a ratio of red to green fluorescence intensities generated by JC-1 staining. This ratio is dependent only on the $\Delta \psi_{\mathrm{m}}$ and not on other factors such as mitochondrial size, shape, and density.

Relative gene expression. Total RNA was isolated from cells using a TRIzol ${ }^{\circledR}$ Plus RNA Purification System (Life Technologies, Carlsbad, CA, USA). The quality of RNA was confirmed by analysis on the NanoDrop (Thermo Fisher Scientific, Wilmington, DE, USA). One microgram of total RNA was reverse transcribed using a reverse transcription kit (High Capacity cDNA Reverse Transcription Kit (Applied Biosystems, Carlsbad, CA, USA) with random primers. Subsequently, cDNA was subjected to real-time PCR. Quantitative real-time polymerase chain reaction (qPCR) was performed with the TaqMan ${ }^{\circledR}$ Gene Expression Assays, according to the manufacturer's protocol using TaqMan ${ }^{\circledR}$ primers for SIRT1 (Hs01009006_m1) and SIRT3 (Hs00953477_m1) (Applied Biosystems). As a reference gene, expression of 18SrRNA was used (Hs03003631_g1) (Applied Biosystems). Amplification was performed using the continuous fluorescence detection system 7900 HT Fast Real Time PCR system (Applied Biosystems). Data were obtained in a form of sigmoid amplification plots in which fluorescence was plotted against the number of cycles. The threshold cycle (CT) served as a measurement of the starting template amount in each sample. Expression ratio was calculated as normalized CT difference between the control probe and the sample. 
Histone deacetylases activity. Nuclear fraction was extracted from CHUBS7 cells using Nuclear Extraction Kit according to the protocol supplied by the manufacturer (Merck Millipore, Darmstadt, Germany). The protein concentration was determined by Total Protein Kit, Micro Lowry, Peterson's Modification (Sigma). Each nuclear extract sample $(10 \mu \mathrm{g})$ was pipetted into four microplate wells, and was run in duplicates with and without addition of trichostatin A (TSA). Histone deacetylases' activity was detected using colorimetric HDAC Assay Kit (Millipore), according to the protocol supplied by the manufacturer. Briefly, samples were incubated with HDAC assay substrate for 60 minutes at $37^{\circ} \mathrm{C}$, allowing deacetylation of the substrate. Next, the activator solution, incubated for 20 minutes at RT, released the $p$-nitroanilide from deacetylated substrate. Colorimetric $p$ nitroanilide was measured in a plate reader (Multiscan) at $405 \mathrm{~nm}$. The HDAC activity was calculated using a standard curve prepared with an assay standard and normalized to protein content.

Statistical analysis. All of data were expressed as the mean +S.D. from five independent experiments measured in triplicate. Calculation of relative gene expression was performed using the comparative CT method. Statistical significances for comparisons between treated and control cell samples were determined by the unpaired $t$-test using Statistica 10.0 PL software.

\section{RESULTS}

\section{Cell differentiation}

The morphology of cultured CHUBS7 cells and lipid droplets formation were observed with the light microscopy. After 21 days of culture, the cells were stained with Oil Red-O. Large lipid droplets stained red, and filled the greater part of the cells (Fig. 1). The staining confirmed that preadipocytes differentiated into mature, functional adipocytes.

\section{Oxygen consumption}

The protocol for oxygen consumption rate (OCR) measurement in the intact cells (Fig. 2) included in sequence: (I) a 10-min period of routine respiration (routine), reflecting the aerobic metabolic activity under cellular routine conditions, (II) oligomycin (final concentration $2 \mu \mathrm{g} / \mathrm{ml}$ ) -inhibited respiration (oligo), which is caused mainly by compensation for the proton leak after inhibition of ATP synthase; (III) FCCP ( $p$-trifluoromethoxy carbonyl cyanide phenyl hydrazone) titration (1.5$3.0 \mu \mathrm{M}$ ), which yields the maximum stimulated respiration, as a measure of electron transport system capacity of uncoupled mitochondria; (IV) antimycin A $(12 \mu \mathrm{M})$ and rotenone $(3 \mu \mathrm{M})$, that inhibit mitochondrial respiratory complexes III and I, respectively (Fig. 2).

Basal OCR of control and Ex-4 treated cells did not differ significantly. When the non-mitochondrial oxygen consumption, measured after full inhibition of mitochondrial electron transport chain by antimycin $\mathrm{A}$ and rotenone, was subtracted, the routine mitochondrial respiration was increased in the Ex-4 treated cells (Fig. 3A). Further analysis after inhibition of the ATP synthase by oligomycin revealed that exendin-4 enhanced non-ATP linked OCR, but did not change ATP-linked OCR (Fig. 3B). After stimulation of the
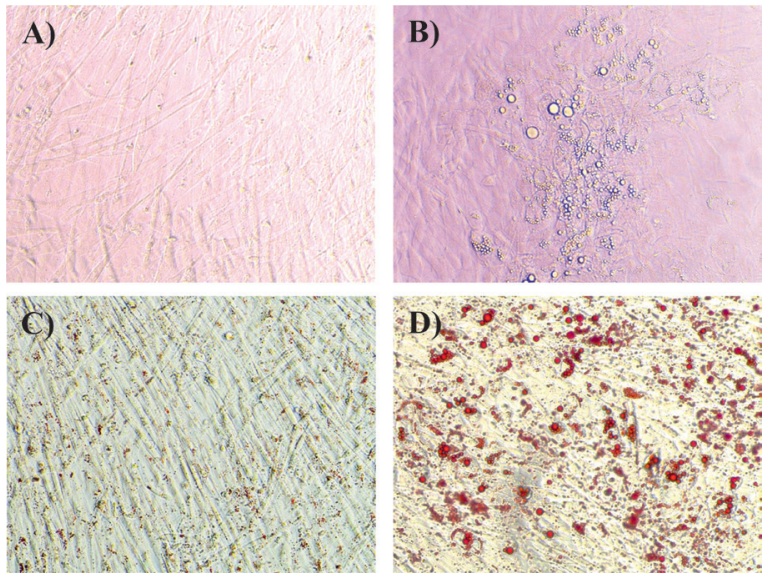

Figure 1. Human ChubS7 preadipocytes prior to differentiation without staining (A) and with Oil Red-O staining (C); andChubS7 cells after 21 days of differentiation into adipocytes without staining (B) and with Oil Red-O staining (D); magnification 200x.

uncoupling of electron transport chain from ATP syntesis in mitochondria by FCCP, the increased maximal mitochondrial OCR and increased reserved capacity in Ex-4 treated cells were found (Fig. 3C). The effects of exendin-4 on oxygen consumption rates were abolished when exendin-9 was added to the cells.

\section{Intracellular ATP content}

The intracellular ATP levels measured by luminometric method were comparable in the exendin-4 treated cells, exendin-9 treated cells and control adipocytes (Fig. 3D). These results confirm that the observed increased oxygen consumption by mitochondria was not associated with excessive ATP syntesis, although the energy homeostasis was maintained.

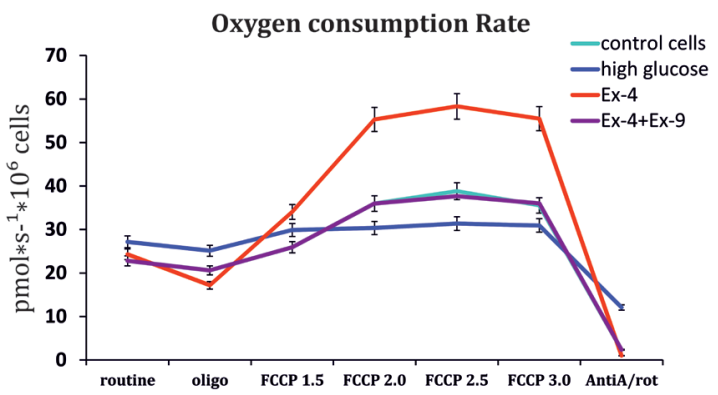

Figure 2. An example of oxygen consumption rate trace (OCR; pmol oxygen per minute per $1 \times 10^{6}$ cells, mean \pm S.D. from 5 experiments) of CHUBS7 cells.

Each line represents oxygen consumption by $1 \times 10^{6}$ adipocytes. Data were digitally recorded using DatLab4 software where oxygen flux was calculated as the negative time derivative of oxygen concentration (Oxygraph-2k, Oroboros Instruments). Compounds were added in the following sequence: oligomycin $(2 \mu \mathrm{g} /$ $\mathrm{ml})$, FCCP titration $(1.5-3.0 \mu \mathrm{M})$, antimycine $\mathrm{A}(12 \mu \mathrm{M})$ + rotenone $(3 \mu \mathrm{M})$. Routine-oxygen consumption without any inhibitors. Control cells-untreated CHUBS7 cells suspended in basal medium containing $4.5 \mathrm{mM}$ glucose; high glucose-untreated CHUBS7 cells cultured for the last $24 \mathrm{~h}$ and suspended in medium containing $25 \mathrm{mM}$ glucose; Ex-4-CHUBS7 cells treated with GLP-1R agonist exendin-4 (100 nM, $24 \mathrm{~h})$ suspended in basal medium containing $4.5 \mathrm{mM}$ glucose; Ex-4+Ex-9-CHUBS7 cells treated with GLP-1R agonist exendin-4 (100 nM, $24 \mathrm{~h})$ along with GLP-1R antagonist exendin-9 (100 nM, $24 \mathrm{~h})$ suspended in basal medium containing $4.5 \mathrm{mM}$ glucose. Abbreviations: oligo, oligomycin, inhibitor of ATP synthase; FCCP ( $p$-trifluoromethoxy carbonyl cyanide phenyl hydrazone), uncoupler stimulating oxygen consumption; AntiA/rot, antimycin $A$ and rotenone, inhibitors of mitochondrial respiratory complex III and I, respectively. 

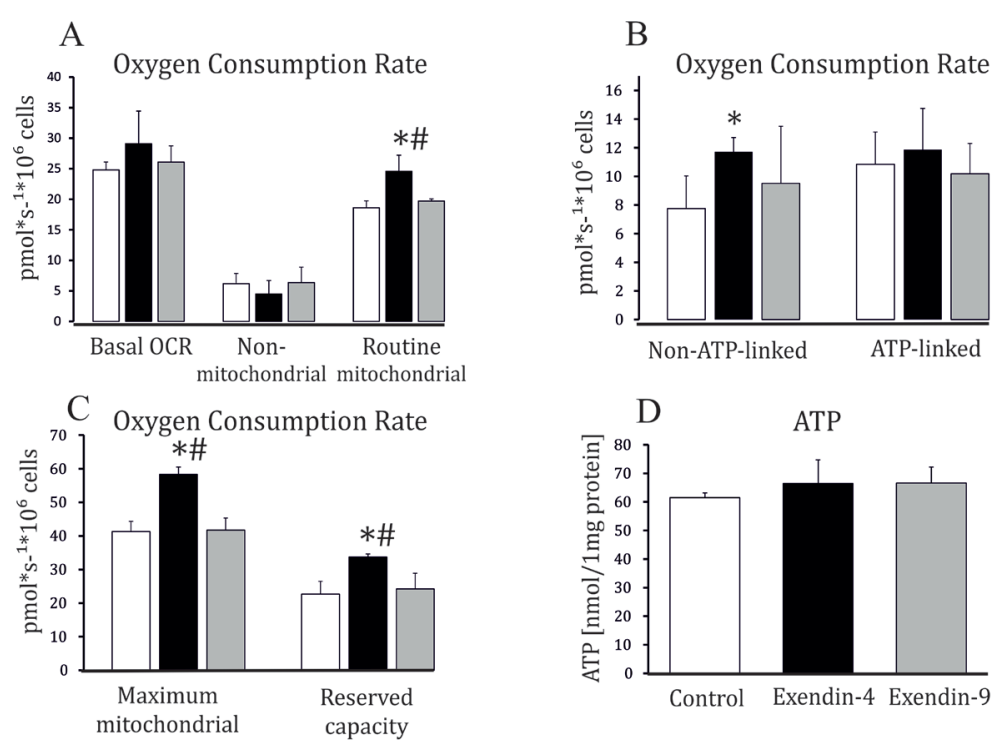

$\square$ Control

Ex-4

Ex-4 + Ex-9

Figure 3. Mitochondrial respiration measured by high resolution respirometry (Oxygraph-2k, Oroboros Instruments) in CHUBS7 control cells, exendin-4 (100 nM, 24 h) treated cells (Ex-4) and exendin-4 with exendin-9 (100 nM, 24 h) treated cells (Ex-4+Ex-9).

(A) basal oxygen consumption rate (OCR), non-mitochondrial OCR (after inhibition of mitochondrial electron transport chain by antimycin A and rotenone) and routine mitochondrial OCR. (B) Not-ATP-linked OCR and ATP-linked OCR. ATP-linked OCR was calculated as the difference between routine OCR and OCR measured after inhibition of ATP synthase by oligomycin. Non-ATP-linked oxygen consumption rate (OCR) was calculated as the difference between routine and ATP-linked OCR. (C) Maximum mitochondrial OCR and reserved capacity. Maximum OCR was determined by subtracting the non-mitochondrial OCR from the maximal reading following addition of FCCP ( $p$-trifluoromethoxy carbonyl cyanide phenyl hydrazone). Reserve capacity was calculated by subtracting the routine OCR from the maximal oxygen consumption after the addition of FCCP. (D) Intracellular concentration of ATP measured by a luminometric method, normalized to protein content in the cell lysate. Data presented as mean + S.D. from 5 experiments; ${ }^{*} p<0.05$ compared to control, $\# p<0.05$ compared to Ex-4+Ex-9 group.

\section{Mitochondrial membrane potential $\left(\Delta \psi_{\mathrm{m}}\right)$}

Mitochondrial membrane potential was measured by JC-1 staining. The ratio of red to green fluorescence intensities generated by JC-1 staining was reduced by $17 \% \quad(n=5, p<0.05)$ indicating that the mitochondrial membrane potential was slightly decreased in the Ex-4 treated cells when compared to the control. A reduced signal from an orange-fluorescent J-aggregate that is associated with hyperpolarized membrane potentials and indicates mild mitochondrial ETC uncoupling, was recorded in the Ex-4 treated cells (Fig. 4).

\section{Gene expression}

Exendin-4 was found to up-regulate two genes coding for sirtiuns (class III histone deacetylase): SIRT1 coding for sirtuin 1 and SIRT3 coding for sirtuin 3 (Fig. 5A, B). This effect was abolished when exendin-9 was added to the cells.

\section{Flow cytometry analysis JC-1 staining}

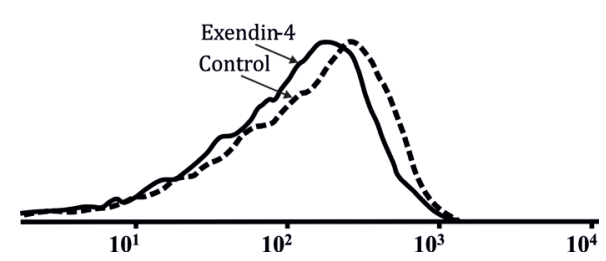

Figure 4. Flow cytometry analysis of mitochondrial membrane potential of CHUBS7 adipocytes by JC-1 staining (FACSCanto II, Becton Dickinson).

Reduced signal from an orange-fluorescent J-aggregate in exendin-4 (100 nM, $24 \mathrm{~h})$ treated cells (Ex-4) compared to control CHUBS7 cells.
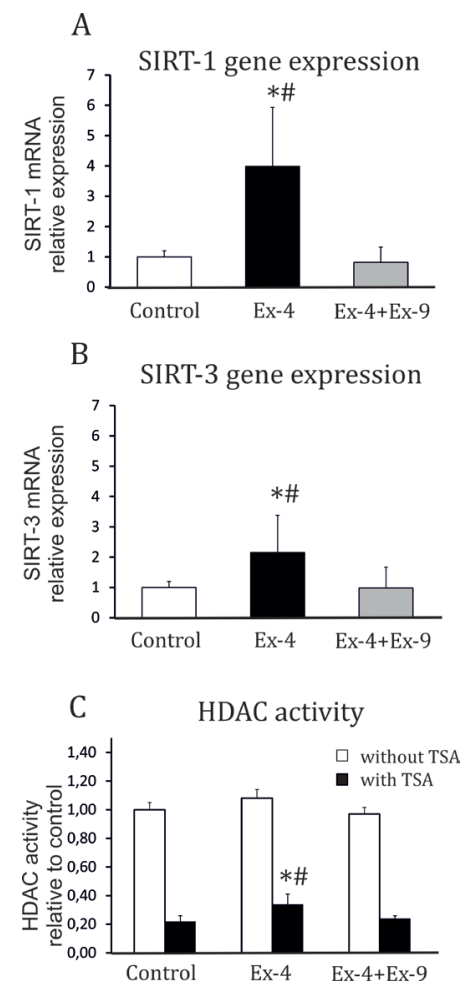

Figure 5. Relative expression of (A) SIRT1 and (B) SIRT3 genes measured by real-time RT-PCR (18SrRNA was used as a reference gene); (C) histone deacetylases' (HDAC) activity measured by colorimetric HDAC Assay Kit (Millipore) in nuclear extracts (10 $\mu \mathrm{g})$ in CHUBS7 control cells, exendin-4 (100 nM, $24 \mathrm{~h})$ treated cells (Ex-4) and exendin-4 with exendin-9 (100 nM, $24 \mathrm{~h})$ treated cells $(E x-4+E x-9)$. Data presented as mean +S.D. from 5 experiments; ${ }^{*} p<0.05$ compared to control, $\# p<0.05$ compared to Ex4+Ex-9 group. 


\section{Histone deacetylases' activity}

There were no significant differences between the exendin- 4 treated and untreated adipocytes in the total activity of histone deacetylases measured in the nuclear extracts (Fig. 5C). Nevertheless, when the trichostatin A, an inhibitor of class I HDAC and class II HDAC, was added to the nuclear samples, the activity of trichostatin A insensitive HDAC was enhanced in the exendin-4 treated adipocytes when compared to the control adipocytes. This indirectly indicates an increased activity of class III histone deacetylases, i.e. the sirtuins (1-7).

\section{DISCUSSION}

The effect of GLP-1 receptor signaling in central nervous system on stimulation of brown adipose tissue thermogenesis through adrenergic neurons in rodents is well documented, but these results do not exclude the possibility of direct influence of GLP-1 on adipocyte browning (Lockie et al., 2012; Beiroa et al., 2014). While some reports from the rodent studies confirm this hypothesis (Mostafa et al., 2015; Xu et al., 2016), other reports suggest that increased BAT thermogenesis did not play a significant role in the food intake-independent body weight lowering effect of GLP-1RAs (Heppner et al., 2015; Chae et al. 2015).

A few studies had indicated direct influence of exendin-4 on mitochondrial function. Recently, a GLP-1RA (liraglutide) specific reduction of lipid content in the liver was reported, along with a decreased expression of major elements involved in lipogenesis, peroxisomal $\beta$-oxidation and lipid flux (Decara et al., 2016). In the INS-1 rat pancreatic beta cell line, exendin-4 prevented cytokine induced apoptosis through counter-regulation of the reduced abundance of electron transport chain proteins (Tews et al., 2009). Exendin-4 was also found to increase mitochondrial mass (Kang et al., 2015). A very recent in vitro study had shown that exendin-4 increases basal and fatty acid stimulated oxygen consumption rate, as well as increased expression of thermogenic UCP1 and PPAR- $\alpha$ in differentiated muscle cells (Choung et al., 2017). Exendin-4 improved mitochondrial function by normalization of citrate synthase activity, mitochondrial oxidative phosphorylation and supercomplex formation in mice after heart failure, and the effects were abolished by GLP-1 antagonist, exendin-9 (Takada et al., 2016). Mechanisms by which exendin-4 increases cardiomyoblasts survival also involve improvement of mitochondrial respiration and suppression of the opening of mitochondrial permeability transition pore (DeNicola et al., 2014).

In our study, exendin-4 stimulated the mitochondrial routine and maximal respiration, increased the reserved capacity and preserved intracellular ATP level in the CHUBS7 adipocytes. It is hypothesized that a reserve capacity exists as a compensation mechanism for cells when presented with increased workload or as a stress response (Cannon \& Nedergaard, 2004; Dranka et al., 2010). Indeed, uncoupling can be stimulated by either high levels of cellular/mitochondrial ROS or by circulating free fatty acids (FFA) (Jarmuszkiewicz et al., 2004; Sluse et al., 2006). The effects of exendin-4 on mitochondrial membrane potential and mild uncoupling reported here, may explain the protective role of GLP-1 (secreted physiologically in response to food intake) to adapt to the metabolic stress occurring in the postprandial period.

In the study presented here, exendin-4 up-regulated mRNA expression of SIRT1 and SIRT3, along with the bioenergetic effects in the CHUBS7 human adipocyte cell line. Sirtuins belong to class III HDAC and thus regulate a number of key metabolic enzymes that are acetylated, malonylated, or succinylated in mitochondria in response to environmental stimuli (Imai et al., 2010; Chalkiedaki et al., 2012). Sirtuin1 (Sirt1) extends lifespan and is involved in energy metabolism (Frye, 2000). Sirtuin 3 (Sirt3), preferentially localized in mitochondria, targets enzymes of the respiratory chain, tricarboxylic acid cycle, fatty acid $\beta$-oxidation and ketogenesis (Hirschey et al., 2010; Giralt \& Villarroya, 2012). Our results for SIRT1 and SIRT 3 expression are in line with a recent report that exendin-4 up-regulates adiponectin in adipocytes through the Sirt1/Foxo-1 signaling pathway (Wang et al., 2017). Similarly, exendin-4 increased lipolysis and fatty acid oxidation by up-regulating SIRT1 expression and activity in differentiated 3T3-L1 adipocytes (Xu et al., 2016). These findings, along with our results, give the basis for the hypothesis that GLP-1R agonist may promote brown remodeling of WAT in a SIRT1dependent manner. Discovery of the involvement of sirtuin 1 in the exendin- 4 mechanism of action in adipocytes is of great importance in the light of data confirming depleted sirtuin levels in obesity (Mariani et al., 2016).

In our study, exendin-4 not only up-regulated SIRT1 and SIRT3 mRNA expression in the CHUBS7 adipocytes, but also increased the class III HDAC activity, although total HDAC activity was not affected. In a recent paper, total HDAC activity was reported to be decreased in visceral adipose tissue of obese human subjects when compared to normal weight subjects. Decreased Hdac5 and Hdac6 expression has been shown in adipocytes from obese human subjects, as well as from obese mice (Bricambert et al., 2016). Activation of sirtuins by exendin-4 was also observed in hepatocytes and rat retinal cells (Lee et al., 2014; Zeng et al., 2016). Thus the restoration of proper sirtuin activity may be one of the mechanisms of pleiotropic effects of GLP-1RAs.

Recently, there has been observed a growing interest in inducible brown-like adipocytes ("beige") in white adipose tissue depots in response to appropriate stimuli. Beige adipocytes have characteristics similar to brown adipocytes, in particular the capacity for uncoupled respiration. Utilization of nutrients by beige adipocytes improves insulin sensitivity and glucose tolerance, but their amount in overweight and obese individuals is reduced (Loyd \& Obici, 2014). Thus, induction of browning of the white fat represents an attractive potential strategy for the management and treatment of obesity and related complications (Bonet et al., 2013). In this paper, we have found that exendin-4 stimulates oxygen consumption and mitochondrial uncoupling in human adipocytes, and thus switches mitochondrial bioenergetics towards energy expenditure. Detailed studies on human adipose tissue are needed to confirm the initial hypothesis that exendin-4 could directly induce browning of the white adipose tissue in humans.

This paper makes contribution to the field of study on the pleiotropic effects of incretin mimetics. The results indicate stimulation of mitochondrial bioenergetics as the effect of exendin-4 action in human adipocytes. Enhanced expression of sirtuins (1 and 3) may elucidate the mechanism of exendin- 4 action in human adipocytes, although further studies are needed to investigate the causal relationship of sirtuin and mitochondrial respiration in this model. The results contribute to the understanding of the GLP-1RAs induced weight loss in patients, which results not only from a decreased energy intake but also from an increased resting energy expenditure. 


\section{Conflicts of interest}

The authors declare that they have no conflicts of interest.

\section{Acknowledgements}

The authors wish to acknowledge the excellent technical assistance provided by Urszula Ciałowicz.

This work was supported by Grant no. K/ ZDS/004496 from the Jagiellonian University Medical College.

\section{REFERENCES}

Anandhakrishnan A, Korbonits M (2016) Glucagon-like peptide 1 in the pathophysiology and pharmacotherapy of clinical obesity. World I Diabetes 7: 572-598. doi: 10.4239/wjd.v7.i20.572

Beiroa D, Imbernon M, Gallego R, Senra A, Herranz D, Villarroya F, Serrano M, Fernø J, Salvador J, Escalada J, Dieguez C, Lopez M, Frühbeck G, Nogueiras R (2014) GLP-1 agonism stimulates brown adipose tissue thermogenesis and browning through hypothalamic AMPK. Diabetes 63: 3346-3358. doi: 10.2337/db14-0302

Bonet ML, Oliver P, Palou A (2013) Pharmacological and nutritional agents promoting browning of white adipose tissue. Biochim Biophys Acta 1831: 969-985. doi: 10.1016/j.bbalip.2012.12.002

Bricambert J, Favre D, Brajkovic S, Bonnefond A, Boutry R, Salvi R, Plaisance V, Chikri M, Chinetti-Gbaguidi G, Staels B, Giusti V, Caiazzo R, Pattou F, Waeber G, Froguel P, Abderrahmani A (2016) Impaired histone deacetylases 5 and 6 expression mimics the effects of obesity and hypoxia on adipocyte function. Mol Metab 5: 1200-1207

Buteau J, El-Assaad W, Rhodes CJ, Rosenberg L, Joly E, Prentki M (2004) Glucagon-like peptide-1 prevents beta cell glucolipotoxicity. Diabetologia 47: 806-815

Butler PC, Dry S, Elashoff R (2010) GLP-1-based therapy for diabetes: what you do not know can hurt you. Diabetes CareV 33: 453-455. doi: $10.2337 / \mathrm{dc} 09-1902$

Cannon B, Nedergaard J (2004) Brown adipose tissue: function and physiological significance. Physiol Rev 84: 277-359

Chae YN, Kim TH, Kim MK, Shin CY, Jung IH, Sohn YS, Son MH (2015) Beneficial effects of evogliptin, a novel dipeptidyl peptidase 4 inhibitor, on adiposity with increased Ppargc1a in white adipose tissue in obese mice. PLoS One 10: e0144064. doi: 10.1371/journal. pone. 0144064

Chalkiadaki A, Guarente L (2012) Sirtuins mediate mammalian metabolic responses to nutrient availability. Nat Rev Endocrinol 8: 287296. doi: 10.1038/nrendo.2011.225.

Choung JS, Lee YS, Jun HS (2017) Exendin-4 increases oxygen consumption and thermogenic gene expression in muscle cells. $J$ Mol Endocrinol 58: 79-90. doi: 10.1530/JME-16-0078

Decara J, Arrabal S, Beiroa D, Rivera P, Vargas A, Serrano A, Pavón FJ, Ballesteros J, Dieguez C, Nogueiras R, Rodríguez de Fonseca F, Suárez J (2016) Antiobesity efficacy of GLP-1 receptor agonist liraglutide is associated with peripheral tissue-specific modulation of lipid metabolic regulators. Biofactors 42: 600-611. doi: 10.1002/ biof.1295

DeNicola M, Du J, Wang Z, Yano N, Zhang L, Wang Y, Qin G, Zhuang S, Zhao TC (2014) Stimulation of glucagon-like peptide-1 receptor through exendin-4 preserves myocardial performance and prevents cardiac remodeling in infarcted myocardium. Am J Physiol Endocrinol Metab 307: E630-E643. doi: 10.1152/ajpendo.00109.2014

Dranka BP, Hill BG, Darley-Usmar VM (2010) Mitochondrial reserve capacity in endothelial cells: The impact of nitric oxide and reactive oxygen species. Free Radic Biol Med 48: 905-914. doi: 10.1016/j.freeradbiomed.2010.01.015

Drucker DJ (2006) The biology of incretin hormones. Cell Metab 3: 153-165

Drucker DJ, Sherman SI, Gorelick FS, Bergenstal RM, Sherwin RS, Buse JB (2010) Incretin-based therapies for the treatment of type 2 diabetes: evaluation of the risks and benefits. Diabetes Care 33: 428-433

Dunham-Snary KJ, Sandel MW, Westbrook DG, Ballinger SW (2014) A method for assessing mitochondrial bioenergetics in whole white adipose tissues. Redox Biol 2: 656-660. doi: 10.1016/j.redox.2014.04.005

Færch K, Torekov SS, Vistisen D, Johansen NB, Witte DR, Jonsson A, Pedersen O, Hansen T, Lauritzen T, Sandbæk A, Holst JJ, Jørgensen ME (2015) GLP-1 response to oral glucose is reduced in prediabetes, screen-detected type 2 diabetes, and obesity and influenced by sex: The ADDITION-PRO Study. Diabetes 64: 2513-2525. doi: $10.2337 / \mathrm{db} 14-1751$
Feher M, Vega-Hernandez G, Mocevic E, Buysse B, Myland M, Power GS, Nystrup Husemoen LL, Kim J, Witte DR (2017) Effectiveness of liraglutide and lixisenatide in the treatment of type 2 diabetes: Real-World Evidence from The Health Improvement Network (THIN) Database in the United Kingdom. Diabetes Ther doi: $10.1007 / \mathrm{s} 13300-017-0241-z$. [Epub ahead of print]

Fehmann HC, Habener JF (1992) Insulinotropic hormone glucagonlike peptide-I(7-37) stimulation of proinsulin gene expression and proinsulin biosynthesis in insulinoma beta TC-1 cells. Endocrinology 130: 159-166

Frye RA (2000) Phylogenetic classification of prokaryotic and eukaryotic Sir2-like proteins. Biochem Biophys Res Commun 273: 793-798

Giralt A, Villarroya F (2012) SIRT3, a pivotal actor in mitochondrial functions: metabolism, cell death and aging. Biochem J 444: 1-10. doi: 10.1042/BJ20120030

Heppner KM, Marks S, Holland J, Ottaway N, Smiley D, Dimarchi R, Perez-Tilve D (2015) Contribution of brown adipose tissue activity to the control of energy balance by GLP-1 receptor signalling in mice. Diabetologia 58: 2124-2132. doi: 10.1007/s00125-015-3651-3

Hirschey MD, Shimazu T, Goetzman E, Jing E, Schwer B, Lombard DB, Grueter CA, Harris C, Biddinger S, Ilkayeva OR, Stevens RD, Li Y, Saha AK, Ruderman NB, Bain JR, Newgard CB, Farese RV Jr, Alt FW, Kahn CR, Verdin E (2010) SIRT3 regulates mitochondrial fatty-acid oxidation by reversible enzyme deacetylation. Nature 464: 121-125. doi: $10.1038 /$ nature 08778

Imai S, Guarente L (2010) Ten years of NAD-dependent SIR2 family deacetylases: implications for metabolic diseases. Trends Pharmacol Sci 31: $212-220$

Jarmuszkiewicz W, Navet R, Alberici LC et al (2004) Redox state of endogenous coenzyme $\mathrm{q}$ modulates the inhibition of linoleic acidinduced uncoupling by guanosine triphosphatein isolated skeletal muscle mitochondria. J Bioenerg Biomembr 36: 493-502

Kang MY, Oh TJ, Cho YM (2015) Glucagon-Like Peptide-1 Increases Mitochondrial Biogenesis and Function in INS-1 Rat In sulinoma Cells. Endocrinol Metab (Seoul) 30: 216-220. doi: 10.3803/ EnM.2015.30.2.216

le Roux CW, Astrup A, Fujioka K, Greenway F, Lau DC, Van Gaal L, Ortiz RV, Wilding JP, Skjøth TV, Manning LS, Pi-Sunyer, X SCALE Obesity; Prediabetes NN8022-1839 Study Group (2017) 3 years of liraglutide versus placebo for type 2 diabetes risk reduction and weight management in individuals with prediabetes: a randomised, double-blind trial. Lancet doi: 10.1016/S01406736(17)30069-7. [Epub ahead of print]

Lee J, Hong SW, Park SE, Rhee EJ, Park CY, Oh KW, Park SW, Lee WY (2014) Exendin-4 attenuates endoplasmic reticulum stress through a SIRT1-dependent mechanism. Cell Stress Chaperones 19: 649-656. doi: 10.1007/s12192-013-0490-3.

Li Y, Hansotia T, Yusta B, Ris F, Halban PA, Drucker DJ (2003) Glucagon-like peptide-1 receptor signaling modulates beta cell apoptosis. I Biol Chem 278: 471-478

Lockie SH, Heppner KM, Chaudhary N, Chabenne JR, Morgan DA, Veyrat-Durebex C, Ananthakrishnan G, Rohner-Jeanrenaud F, Drucker DJ, DiMarchi R, Rahmouni K, Oldfield BJ, Tschöp MH, Perez-Tilve D (2012) Direct control of brown adipose tissue thermogenesis by central nervous system glucagon-like peptide-1 receptor signaling. Diabetes 61: 2753-2762. doi: 10.2337/db11-1556

Loyd C, Obici S (2014) Brown fat fuel use and regulation of energy homeostasis. Curr Opin Clin Nutr Metab Care 17: 368-372. doi: 10.1097/MCO.0000000000000063

Lundkvist P, Sjöström CD, Amini S, Pereira MJ, Johnsson E, Eriksson JW (2017) Dapagliflozin once-daily and exenatide once-weekly dual therapy: A 24-week randomized, placebo-controlled, phase II study examining effects on body weight and prediabetes in obese adults without diabetes. Diabetes Obes Metab 19: 49-60. doi: 10.1111/ dom.12779

Majumdar ID, Weber HC (2010) Gastrointestinal regulatory peptides and their effects on fat tissue. Curr Opin Endocrinol Diabetes Obes 17: 51-56

Mariani S, Di Rocco G, Toietta G, Russo MA, Petrangeli E, Salvatori L (2016) Sirtuins 1-7 expression in human adipose-derived stem cells from subcutaneous and visceral fat depots: influence of obesity and hypoxia. Endocrine [Epub ahead of print]

McAdam-Marx C, Nguyen H, Schauerhamer MB, Singhal M, Unni S, Ye X, Cobden D (2016) Glycemic control and weight outcomes for exenatide once weekly versus liraglutide in patients with type 2 diabetes: a 1-year retrospective cohort analysis. Clin Ther 38: 2642-2651. doi: 10.1016/j.clinthera.2016.11.003

Morano S, Romagnoli E, Filardi T, Nieddu L, Mandosi E, Fallarino M, Turinese I, Dagostino MP, Lenzi A, Carnevale V (2015) Shortterm effects of glucagon-like peptide 1 (GLP-1) receptor agonists on fat distribution in patients with type 2 diabetes mellitus: an ultrasonography study. Acta Diabetol 52: 727-732. doi: 10.1007/s00592014-0710-Z

Mostafa AM, Hamdy NM, El-Mesallamy HO, Abdel-Rahman SZ (2015) Glucagon-like peptide 1 (GLP-1)-based therapy upregulates 
LXR-ABCA1/ABCG1 cascade in adipocytes. Biochem Biophys Res Commun 468: 900-905. doi: 10.1016/j.bbrc.2015.11.054

Muoio DM, Newgard CB (2008) Mechanisms of disease: molecular and metabolic mechanisms of insulin resistance and beta-cell failure in type 2 diabetes. Nat Rev Mol Cell Biol 9: 193-205. doi: 10.1038/ nrm2327

Østergaard L, Frandsen CS, Madsbad S (2016) Treatment potential of the GLP-1 receptor agonists in type 2 diabetes mellitus: a review. Expert Rev Clin Pharmacol 9: 241-265. doi: 10.1586/17512433.2016.1121808

Pastel E, Joshi S, Knight B, Liversedge N, Ward R, Kos K (2016) Effects of Exendin- 4 on human adipose tissue inflammation and ECM remodelling. Nutr Diabetes 6: e235. doi: 10.1038/nutd.2016.44

Sluse FE, Jarmuszkiewicz W, Navet R, Douette P, Mathy G, SluseGoffart CM (2006) Mitochondrial UCPs: new insights into regulation and impact. Biochim Biophys Acta 1757: 480-485

Szendroedi J, Esther Phielix \& Michael Roden (2011) The role of mitochondria in insulin resistance and type 2 diabetes mellitus. Nature Rev Endocrinol 8: 92-103 doi:10.1038/nrendo.2011.138

Takada S, Masaki Y, Kinugawa S, Matsumoto J, Furihata T, Mizushima W, Kadoguchi T, Fukushima A, Homma T, Takahashi M, Harashima S, Matsushima S, Yokota T, Tanaka S, Okita K, Tsutsui H (2016) Dipeptidyl peptidase-4 inhibitor improved exercise capacity and mitochondrial biogenesis in mice with heart failure via activation of glucagon-like peptide-1 receptor signalling. Cardiovasc Res 111: 338-347. doi: 10.1093/cvr/cvw182
Tews D, Lehr S, Hartwig S, Osmers A, Paslack W, Eckel J (2009) Anti-apoptotic action of exendin-4 in INS-1 beta cells: comparative protein pattern analysis of isolated mitochondria. Horm Metab Res 41: 294 -301. doi: 10.1055/s-0028-1105911

Wadden TA, Hollander P, Klein S, Niswender K, Woo V, Hale PM, Aronne L; NN8022-1923 Investigators (2013) Weight maintenance and additional weight loss with liraglutide after low-calorie-diet-induced weight loss: the SCALE Maintenance randomized study. Int J Obes (Lond) 37: 1443-1451. doi: 10.1038/ijo.2013.120

Wang A, Li T, An P, Yan W, Zheng H, Wang B, Mu Y (2017) Exendin-4 upregulates adiponectin level in adipocytes via Sirt1/Foxo1 signaling pathway. PLoS One 12: e0169469. doi: 10.1371/journal. pone.0169469

Xu F, Lin B, Zheng X, Chen Z, Cao H, Xu H, Liang H, Weng J (2016) GLP-1 receptor agonist promotes brown remodelling in mouse white adipose tissue through SIRT1. Diabetologia 59: 10591069. doi: 10.1007/s00125-016-3896-5

Zeng Y, Yang K, Wang F, Zhou L, Hu Y, Tang M, Zhang S, Jin S, Zhang J, Wang J, Li W, Lu L, Xu GT (2016) The glucagon like peptide 1 analogue, exendin-4, attenuates oxidative stress-induced retinal cell death in early diabetic rats through promoting Sirt1 and Sirt3 expression. Exp Eye Res 151: 203-211. doi: 10.1016/j. exer.2016.05.002 